\title{
Obsolescence and Modernization in the Growth Process *
}

\author{
Raouf Boucekkine $^{\dagger} \quad$ Fernando del Río Omar Licandro $^{\ddagger}$
}

November, 2002

\begin{abstract}
In this paper, an endogenous growth model is built up incorporating Schumpeterian growth and embodied technological progress. Under embodiment, long run growth is affected by the following effects: (i) obsolescence costs add to the user cost of capital, reducing the research effort; and (ii) the modernization of capital through investment raises the incentives to undertake R\&D activities. Applied to the understanding of the growth enhancing role of both capital and $R \& D$ subsidies, we conclude that the positive effect of modernization generally more than compensate the negative effect of obsolescence.
\end{abstract}

Keywords: Shumpeterian growth, Creative destruction, Embodiment, Obsolescence, Modernization.

Journal of Economic Literature: E22, E32, O40.

*We would like to thank Bruno Amable, David de la Croix, Victor Ríos-Rull, the participants at the II Louvain Symposium on Macroeconomic Dynamics and two anonymous referees for their useful comments. Any remaining error is ours. Boucekkine acknowledges the financial support of the Belgian French speaking community (Grant ARC 99/04-235). Finally, del Río and Licandro acknowledge the financial support of the Spanish Ministry of Sciences and Technology (Grant SEC2000-0260).

$\dagger$ Corresponding author. IRES and CORE, Université catholique de Louvain, Place Montesquieu, 3, B-1348 Louvain-la-Neuve (Belgique). E-mail: boucekkine@ires.ucl.ac.be.

$\ddagger$ Universidade de Santiago de Compostela. E-mail: aedelrio@usc.es

§European University Institute and FEDEA. E-mail: omar.licandro@iue.it. 


\section{Introduction}

The role of capital accumulation is a traditional issue in growth and development theory. In the neoclassical framework, investment only matters in the short run, while technological progress is the sole determinant of per-capita growth in the long run. Therefore, subsidizing capital accumulation has no permanent impact on the growth rate. In contrast, facilitating and subsidizing R\&D and/or technology adoption activities fosters long term growth. Typically in R\&D based growth models à la Romer (1990), only subsidies to research activities, which precisely drive technological progress, are effective in boosting growth. However, Howitt and Aghion (1998) show that this result is biased by Romer's assumptions. In particular, the assumption that labor is the sole input in the production of research. Indeed, if the R\&D sector employs capital goods as an input, capital accumulation becomes important for long run growth, and subsidizing capital accumulation is growth enhancing.

This dichotomy between capital accumulation and technological progress was at the heart of the embodiment controversy in the sixties, as recently pointed out by Hercowitz (1998). Supporters of the embodiment hypothesis, Solow (1960) among them, argued that investment is the channel through which innovations are implemented. Hence investment has a modernization role under embodiment, and it should be a decisive determinant of long run growth. Phelps (1962) radically questioned this view. Within an exogenous growth framework with both embodied and disembodied technological progress, he showed that while investment is important for the pace of the growth rate in the short run, it is not so in the long run. However, as stressed by Boucekkine, del Rio and Licandro (2002), Phelp's results are a direct consequence of the exogenous nature of technical progress, at the core of the neoclassical growth theory. In order to understand the critical role of investment for growth and development, an endogenous growth model with embodied technical change is required.

From an empirical point of view, several recent contributions have stressed the role of embodiment in the development process, notably through its modernization dimension. DeLong and Summers (1991) find that countries with higher growth rates are precisely those with higher investment rates in equipment and faster declines in the relative price of equipment. For a sample of seven OECD countries, Wolff (1991) finds that catch-up in total factor productivity is highly correlated with capital accumulation. He also concludes that embodiment plays a central role in this relationship as productivity growth is highly sensitive to the age of the capital stock. Bardhan and Priale (1996) notice the significant difference in the saving rate between Latin America and East Asia, and invoke the modernization role of investment to explain fast economic growth in East Asia and relative stagnation in Latin America. Such a role of embodiment is indeed in DeLong and Summers contribution, since the observed decline in the relative price of equipment captures the embodied nature of technological progress and the associated obsolescence of the pre-existing capital goods (see Greenwood, Hercowitz and Krusell, 1997). 
On a more theoretical ground, some analytical work is already available. In particular, three pioneering contributions are of interest: Krusell (1998), Hsieh (2001) and Bardhan and Priale (1996), the two latter being more connected with the purpose of our work. In the three papers, growth is endogenous and technological progress is embodied in capital goods. Krusell and Hsieh use an explicit R\&D sector à la Romer (1990), ie. with labor as the sole input, and Bardhan and Priale use mainly Arrowian learning-by-doing to endogenize technical progress and growth. We use an endogenous growth set-up with embodied technical change and a Schumpeterian R\&D sector à la Aghion and Howitt (1992). Our paper markedly depart from the above mentioned pioneering contributions in the following:

(i) First of all, the obsolescence mechanisms involved are different. The focus of Krusell's paper is planned obsolescence and the induced sub-optimality of decentralized equilibria. This analysis is made possible by the deterministic nature of $\mathrm{R} \& \mathrm{D}$ decisions. In Hsieh, and Bardhan and Priale, the obsolescence mechanism advocated by these authors is close to the inflationary wage scheme first put forward by Solow et al. (1966). Technological progress pushes wages upward deterministically, which ends up by exhausting the quasi-rents extracted from the existing capital goods under the assumption that their productivity is fixed once for all. This kind of mechanism takes place under a vintage structure when some complementarity between capital and labor exists. Our obsolescence mechanism is at first an obsolescence of technologies. In our stochastic framework, the occurrence of a technological innovation induces a Schumpeterian creative destruction phenomenon, which displaces the existing technologies and lowers the relative price of capital. In contrast to Bardhan and Priale, and Hsieh, there is no finite scrapping time in our model, all capital goods have an infinite lifetime as we don't allow for complementarity between capital and labor. ${ }^{1}$ In our model the obsolescence of capital goods is exclusively captured by the declining relative price of capital adding to the user cost of capital, and reducing the incentives to invest.

(ii) More importantly, there is a clear difference in the description of the modernization role of investment under embodiment. For Bardhan and Priale and Hsieh, ${ }^{2}$ the modernization role of investment shows up in the negative correlation existing between the growth rate and the lifetime of machines. The shorter the lifetime of capital goods, the higher the growth rate. In our model, the lifetime of capital goods is infinite, and hence the modernization mechanism of investment is different. Concretely, we identify a modernization multiplier mechanism based on the average age of capital. This mechanism requires the investment level of the economy to be a determinant of the profitability of the technology sector (which could be an R\&D sector or an adoptionimitation sector in the case of developing countries) to be effective. An increase in the rate of technical progress has multiplicative effects by lowering the average age of

\footnotetext{
${ }^{1}$ To be precise, the benchmark model considered by Hsieh is consistent with capital goods living for ever. However, he adds a complementarity assumption which ultimately allows to obtain an optimally finite lifetime for capital goods.

${ }^{2}$ Krusell is not concerned at all with this issue.
} 
capital, and inducing a further rise in investment, which in turn affects the rate of technological progress and the average age of capital.

There are two main advantages from our treatment of the modernization effects. First of all, it is algebraically trivial in comparison with the corresponding developments in Hsieh and Bardhan and Priale. ${ }^{3}$ Second, it allows us to connect with one of the more important discussions in the embodiment controversy, namely the existence of a negative correlation between growth and the average age of capital reflects the importance of embodiment (see the striking paper of Denison, 1964). However, by definition of the average age of capital, it is a decreasing function of the growth rate: in a high growth economy, the weight of new equipments is high and the average age of capital is small. Such a negative relation is then predicted by any growth model, independently of the embodied or disembodied nature of technical progress. Nonetheless, the modernization of the capital stock associated with the decline of the average age of capital should be more important for growth under embodiment, where technical progress is incorporated in new equipment.

Our paper also makes a contribution to the creative destruction literature. In line with Solow (1960), we introduce capital accumulation into the Aghion and Howitt's 1992 creative destruction model. Aghion and Howitt (1998), section 3.2.4, have already undertaken such a task. However, they treat capital accumulation and technological progress separately: the capital goods used under a technological regime may or may not be re-used when a technological innovation occurs. In our model, the technological advances are incorporated into new capital goods, which is the way embodiment should be modelled. In Aghion and Howitt (1998), section 3.2.4, the embodiment assumption is supposedly reproduced by assuming that the capital goods used under a given technological regime are useless when a new technological innovation occurs. That is, embodiment is assumed to be fully captured by the associated obsolescence costs. In such a context, Aghion and Howitt claim that subsidies are less growth enhancing under embodiment, because any increase in the rate of technological progress should raise the user cost of capital reducing the incentives to undertake research activities. However, we claim that Aghion and Howitt's argument does not capture all the implications of the embodiment assumption since it omits the modernization role of investment in such a context. Moreover, we show that the modernization effects generally offset the growth losses due to obsolescence costs, which improves the growth enhancing role of subsidies. Our analysis traces back indeed to the famous embodiment controversy. In our research-based endogenous growth model, the modernization effect is therefore a fundamental determinant of long run growth. Accordingly, the modernization effect gives a theoretical support to the importance of the embodied question.

This paper is organized as follows. In section 2, the proposed model is solved and its main properties are stressed. In particular, it is compared with the exogenous

\footnotetext{
${ }^{3}$ Indeed, the analytical work is so demanding in Hsieh's paper that the author is only able to give numerical results when the lifetime of capital goods is finite.
} 
growth model with embodied technical change by Greenwood, Hercowitz and Krusell (1997), and the R\&D growth model with physical capital proposed by Howitt and Aghion (1998). The main economic mechanisms, obsolescence and modernization, are discussed. Section 3 is devoted to the analysis of the effects on growth of capital and research subsidies. Sufficient conditions under which the modernization effect dominates the obsolescence effect are stated and interpreted. Section 4 concludes.

\section{The Model}

The model in this paper is based on Aghion and Howitt (1992), and it introduces vintage capital and embodied technical change as in Solow (1960). There are two final sectors, one producing a non durable good, and another producing an investment good. The non durable good is taken as the numeraire. Technology in the non durable sector is Cobb-Douglas on capital and labor, and the non durable good is allocated to consumption and as an input in both the production of intermediate goods and R\&D activities. Technology in the investment goods sector is constant elasticity of substitution on a continuum of intermediate inputs. Both final sectors are competitive. In the intermediate sector a continuum of differentiated goods is produced under monopolistic competition. Technology in this sector only employs non durable goods as inputs, and benefits directly from innovations developed in the R\&D sector. Finally, the R\&D sector is competitive and only employs the non durable good as an input.

The structure of the economy is very similar to the one in the two sector exogenous growth model of Greenwood, Hercowitz and Krusell (1997), where one sector employs capital and labor to produce a non durable good, and the other sector produces an investment good employing the non durable good as the sole input. In our model, the transformation of non durable goods in investment goods requires an intermediate step, i.e., the production of intermediate inputs. In both models, technological progress benefits the investment sector only, and requires new investments to propagate over the whole economy; the so-called embodied nature of technological progress.

Howitt and Aghion (1998) combine the neoclassical growth model à la Solow (1956) and their 1992 creative destruction model, and share some key properties with our model, in particular that quality improvements are the engine of growth and profits in the intermediate sector are the main incentive to innovate. However and differently from our model, Howitt and Aghion assume that technical progress is disembodied: A sole final goods sector produces both consumption and investment goods, and benefits from quality improvements in the intermediate sector. As it is shown in the next, the different nature of technological progress is crucial to understand the different economic mechanisms at work in these two models. 


\subsection{Growth Under Embodiment}

As in the standard optimal growth model, an infinitely lived representative dynasty endowed with $L>0$ units of labor maximizes intertemporal utility. The Euler equation related to the dynasty problem is

$$
\frac{\dot{C}_{t}}{C_{t}}=\frac{1}{\sigma}\left(r_{t}-\rho\right) .
$$

As usual, the growth rate of per-capita consumption, $C_{t}$, depends on the difference between the interest rate $r_{t}$ and the dynasty's discount rate $\rho$, weighted by the inverse of the intertemporal elasticity of substitution, $\sigma>0$ and $\sigma \neq 1$, which is supposed to be constant.

Technology in the investment sector displays constant returns to scale on a continuum of intermediate inputs in the interval $[0,1]$ :

$$
I_{t}=\left(\int_{0}^{1} x_{j t}^{\alpha} \mathrm{d} j\right)^{\frac{1}{\alpha}},
$$

where $I_{t}$ is per-capita investment, $x_{j t}$ is the per-capita amount of the intermediate good $j$ used in the production of the investment good, and $\alpha \in] 0,1[$. The problem of the representative firm in the investment sector is purely static. She takes prices as given and maximizes current profits subject to the technological constraint (2). The optimal demand for the intermediate good $j$ is:

$$
x_{j t}=\left(\frac{p_{j t}}{P_{t}}\right)^{\frac{1}{\alpha-1}} I_{t},
$$

where $P_{t}$ is the price of the investment good and $p_{j t}$ is the price of the $j$ th intermediate good. The so-called 'true price index' associated with technology (2) is given by

$$
P_{t}=\left(\int_{0}^{1} p_{j t}^{\frac{\alpha}{\alpha-1}} \mathrm{~d} j\right)^{\frac{\alpha-1}{\alpha}} .
$$

The technology in the intermediate sector is linear on a sole input, the non durable good. The marginal productivity in the production of the $j$ th intermediate good is $q_{j t}$. The sector is under monopolistic competition and each intermediate good is produced by one firm only. Given the demand function (3), the $j$ th monopolist optimally sets the price

$$
p_{j t}=\frac{1}{\alpha} \frac{1}{q_{j t}}
$$

The markup, $\frac{1}{\alpha}$, is constant and equal for all monopolists, and $\frac{1}{q_{j t}}$ is the marginal cost. From (4) and (5), we can compute the relative price of the investment good 


$$
P_{t}=\frac{1}{\alpha Q_{t}}
$$

where

$$
Q_{t}=\left(\int_{0}^{1} q_{j t}^{\frac{\alpha}{1-\alpha}} \mathrm{d} j\right)^{\frac{1-\alpha}{\alpha}}
$$

is a quality index of the inputs used in the production of the durable good. The relative price of the investment good is an inverse function of the average quality of intermediate inputs. In a stationary growth regime, $Q_{t}$ must be growing at a positive constant rate, implying that the relative price of investment goods must be permanently declining. Notice also that the price of any intermediate good relative to the price of the investment good is $\frac{p_{j t}}{P_{t}}=\frac{Q_{t}}{q_{j t}}$, and only depends on its relative quality. More efficient intermediate goods are sold at smaller prices.

The per-capita amount of non durable goods employed in the production of intermediate goods is given by

$$
X_{t}=\int_{0}^{1} \frac{x_{j t}}{q_{j t}} \mathrm{~d} j=\frac{I_{t}}{Q_{t}} .
$$

The left hand side of this equation can be easily obtained after combination of (3), $\frac{p_{j t}}{P_{t}}=\frac{Q_{t}}{q_{j t}}$ and $(7)$.

In the non durable goods sector, technology is Cobb-Douglas, i.e., $f\left(K_{t}\right)=K_{t}^{\alpha}$, where $K_{t}$ is the per-capita stock of capital. The law of motion of the per-capita capital stock is

$$
\dot{K}_{t}=I_{t}-\delta K_{t}
$$

where $\delta>0$ is the depreciation rate.

In this sector, the representative firm takes prices as given and maximizes the discounted flow of profits subject to these technological constraints. Capital accumulation is subsidized at the rate $\beta_{k}>0$, so that firms face the discount rate $r_{t}-\beta_{k}$. From the first order conditions of this problem, the marginal productivity of capital must be equal to the corresponding user cost:

$$
f^{\prime}\left(K_{t}\right)=P_{t}\left(r_{t}+\delta-\frac{\dot{P}_{t}}{P_{t}}-\beta_{K}\right) .
$$

As expected, changes in the price of investment goods have a negative effect on the user cost of capital. From (6), the decline on investment prices is equal to the growth rate of the quality index, i.e., $-\frac{\dot{P}_{t}}{P_{t}}=\frac{\dot{Q}_{t}}{Q_{t}}$. Quality improvements in the intermediate sector move the technological frontier up, reducing the future price of investment goods and acting as a brake on capital accumulation. This is the so-called obsolescence cost related to embodied technical change. 
At equilibrium, per-capita production of the non durable good is allocated to consumption, $C_{t}$, and as inputs in the production of both the intermediate sector, $X_{t}$, and the $R \& D$ sector, $D_{t}$. All variables are in per-capita terms.

Combining equations (1), (6), (8) to (10) and the equilibrium in the non durable sector, we get

$$
\begin{gathered}
\dot{K}_{t}=Q_{t}\left(K_{t}^{\alpha}-C_{t}-D_{t}\right)-\delta K_{t} \\
\frac{\dot{C}_{t}}{C_{t}}=\frac{1}{\sigma}(\alpha Q_{t} \underbrace{\alpha K_{t}^{\alpha-1}}_{f^{\prime}\left(K_{t}\right)}-\left(\rho+\delta+\gamma_{t}-\beta_{K}\right)),
\end{gathered}
$$

where $\gamma_{t} \equiv \frac{\dot{Q}_{t}}{Q_{t}}$ is the rate of embodied technical change.

This system is very close to the system representing the equilibrium of an optimal growth model with embodied technical change, as in Greenwood, Hercowitz and Krusell (1997). Along a balanced growth path with positive growth, it can be easily shown that the growth rate of consumption is smaller than the growth rate of investment. Consequently, our model reproduces the main empirical facts related to embodiment. First, from (6) the relative price of investment permanently decline at the rate of embodied technical change, $\gamma$. Second, the investment to output ratio permanently increases. $^{4}$

The three main differences between our model and Greenwood, Hercowitz and Krusell are the following. First, the production of the final good may also be allocated to R\&D activities. Second, the obsolescence cost, $\gamma_{t}$, is endogenous. Its behavior is analyzed in the next sub-section. Finally, monopolistic competition in the intermediate goods sector implies that the marginal productivity of capital is multiplied by $\alpha$, the inverse of the markup rate. Under exogenous growth, i.e. $R_{t}=0, \gamma_{t}=\gamma>0$, and perfect competition in the intermediate goods sector, these two equations become equivalent to the dynamic system in Greenwood, Hercowitz and Krusell.

\subsection{Shumpeterian R\&D Activities}

In this section, the rate of embodied technical change is endogenized following Aghion and Howitt (1992). Let $q_{j t}=q^{\kappa_{j t}}$, where $q^{\kappa_{j t}}$ represents the quality grad of the $j$ th intermediate good at time $t, q>0$ being a constant. ${ }^{5} \kappa_{j t}$ represents the number of

\footnotetext{
${ }^{4}$ Based on the economic theory on index numbers, Licandro, Ruiz-Castillo and Durán (2001) find that, in this framework, the growth rate of output must be defined as in NIPA's methodology, i.e., it is approximately equal to a linear combination of the growth rates of consumption and investment. Consequently, the growth rate of output is smaller than the growth rate of investment.

${ }^{5}$ To be more precise, $q$ must be larger than $\frac{1}{\alpha}$. The latter condition states that the difference in quality between two successive innovations should be sufficiently large, that the current innovation displace the previous one.
} 
quality improvements of the $j$ th intermediate good achieved up to date $t$. As usual in this literature, a researcher discovering a new quality grade is supposed to have the monopoly right to produce the good at the obtained quality. Consequently, when a new quality improvement occurs incumbents lose automatically their monopoly rentals. This feature generates a Shumpeterian process of creative destruction.

How does the creative destruction process take place for the $j$ th intermediate good? Let $q^{\kappa_{j}}$ be the leading quality grade at time $t$. If a researcher successfully introduce an innovation at this time, the quality grade increases to $q^{\kappa_{j}+1}$. The innovation is assumed to come out according to a Poisson process, where $\eta_{\kappa_{j}}$ denotes the Poisson arrival rate. The technology in this sector is assumed to be $\eta_{\kappa_{j}}=n_{\kappa_{j}} \phi\left(\kappa_{j}\right)$, where $n_{\kappa_{j}}$ is the amount of non durable goods devoted to research in quality improvements. The Poisson arrival rate $\eta$ is supposed to be a decreasing function of the research task, here captured by $\kappa$. Hence, $\phi^{\prime}(\kappa)<0$. More precisely, we set $\phi(\kappa)=\lambda q^{-(\kappa+1) \frac{\alpha}{1-\alpha}}$, where $\lambda$ is a positive parameter, and the remaining term represents the negative effect of the complexity of the research task on the Poisson arrival rate. This choice is consistent, as it is shown later, with an equilibrium Poisson probability ultimately independent of the complexity of the research task.

The expected value of an innovation discovered at time $t, V_{\kappa_{j}+1, t}$, is equal to the expected flow of profits it generates. The instantaneous profits of the $\kappa_{j}+1$ innovator, for all time $z \geq t$ until she will be displaced by the $\kappa_{j}+2$ innovator, are given by

$$
\pi_{\kappa_{j}+1, z}=\left(p_{j z}-\frac{1}{q^{\kappa_{j}+1}}\right) x_{j z} L=\frac{1-\alpha}{\alpha} \frac{I_{z} L}{q^{\kappa_{j}+1}}\left(\frac{q^{\kappa_{j}+1}}{Q_{z}}\right)^{\frac{1}{1-\alpha}} .
$$

The last equality comes after substitution of $p_{j}$ from (5) and $x_{j}$ from (3), using the condition $\frac{p_{j}}{P}=\frac{Q}{q_{j}}$. Given the embodied nature of technological progress, the benefits of R\&D accrue to the investment sector. Consequently, the instantaneous profits of an innovator depend on the demand for investment goods only, in contrast to Howitt and Aghion where technological progress is disembodied and benefits also the consumption sector. Under embodiment, the scope of $R \& D$ is restricted to the investment sector, enlarging the importance of investment in the growth process.

Then,

$$
V_{\kappa_{j}+1, t}=\int_{t}^{\infty} \pi_{\kappa_{j}+1, z} \mathrm{e}^{-\int_{t}^{z}\left(r_{s}+\eta_{\kappa_{j}+1, s}\right) \mathrm{d} s} \mathrm{~d} z,
$$

where the two exponential terms in the integrand represent respectively the discount factor and the probability of the quality grade $q^{\kappa_{j}+1}$ still leading at time $z>t$.

Let us assume that the research sector is competitive and research is subsidized at the rate $\beta_{R}$. The arbitrage condition for a strictly positive amount of resources spent in $R \& D$ activities stipulates that the marginal cost of research should be equal to the expected present value of profits, that is: 


$$
1-\beta_{R}=\phi\left(\kappa_{j}\right) V_{\kappa_{j}+1, t} .
$$

This arbitrage condition implies $\dot{V}_{\kappa_{j}+1, t}=0$, which yields by differentiation of (11)

$$
V_{\kappa_{j}+1, t}=\frac{1-\alpha}{\alpha} \frac{q^{\left(\kappa_{j}+1\right) \frac{\alpha}{1-\alpha}}}{r_{t}+\eta_{\kappa_{j}+1}} Q_{t}^{\frac{1}{\alpha-1}} I_{t} L
$$

¿From (12) and (13), it turns out that the Poisson arrival rate, $\eta_{\kappa_{j}+1}$, does not depend on the complexity of the research task, that is $\eta_{\kappa_{j}+1}=\eta \forall j$. This means that quality improvements can occur for all types of intermediate goods with the same probability, whatever the quality grade is. This property of the model is entirely due to the specification of function $\phi(\kappa)$, as outlined by Barro and Sala-i-Martin (1995). The Poisson arrival rate $\eta_{\kappa}$ is affected by $\kappa$ in two opposite ways. First, the monopoly profits accruing to an innovator increase with $\kappa$, since its productivity depends directly on it. Secondly, by assumption, the probability of innovating decreases with the difficulty of the task, measured by $\kappa$. When the specification $\phi(\kappa)=q^{-(\kappa+1) \frac{\alpha}{1-\alpha}}$ is adopted, the two effects exactly offset.

As set out above, at equilibrium Poisson arrival rates are equal for all intermediate goods. By the Law of Large Numbers, the average growth rate of $Q(t)$ is

$$
\gamma_{t}=\widetilde{q} \eta_{t},
$$

where $\widetilde{q}=\frac{\alpha}{1-\alpha}\left(q^{\frac{\alpha}{1-\alpha}}-1\right)$. From (13) and (14), the arbitrage condition (12) can be written as

$$
1-\beta_{R}=\lambda \frac{1-\alpha}{\alpha} \frac{Q_{t}^{\frac{1}{\alpha-1}} I_{t} L}{r_{t}+\frac{\gamma t}{\widetilde{q}}} .
$$

Finally, the equilibrium allocation of non durable inputs to the production of $\mathrm{R} \& \mathrm{D}$ activities is given by $D_{t}=\int_{0}^{1} n_{\kappa_{j t}} \mathrm{~d} j$. Since the equilibrium Poisson arrival rates are the same for all intermediate goods, using (14), we get after some trivial algebra:

$$
D_{t}=\frac{1}{\lambda L \widetilde{q}} \gamma_{t} Q_{t}^{\frac{\alpha}{1-\alpha}}
$$

\subsection{Shumpeterian Growth Under Embodiment}

In order to characterize the equilibrium of this economy, the following variable changes are introduced. Concerning non durable consumption and inputs, $z_{t}=Z_{t} Q_{t}^{\frac{\alpha}{\alpha-1}}$ for $Z \in$ $\{C, X, D\}$. Concerning capital and investment, $z_{t}=Z_{t} Q_{t}^{\frac{1}{\alpha-1}}$ for $Z \in\{I, K\}$. Implicit in this transformation is that consumption grows at a smaller rate than both investment 
and capital, a direct implication of embodied technical change. The equilibrium of this economy can be characterized by the following differential equation system, in $r_{t}, \gamma_{t}$, $c_{t}, i_{t}$ and $k_{t}$ :

$$
\begin{gathered}
\frac{\dot{c}_{t}}{c_{t}}=\frac{1}{\sigma}\left(r_{t}-\rho-\sigma \frac{\alpha}{1-\alpha} \gamma_{t}\right), \\
\dot{k}_{t}=i_{t}-\left(\delta+\frac{1}{1-\alpha} \gamma_{t}\right) k_{t}, \\
\alpha k_{t}^{\alpha-1}=\frac{1}{\alpha}\left(r_{t}+\delta+\gamma_{t}-\beta_{K}\right), \\
k_{t}^{\alpha}=c_{t}+i_{t}+\frac{1}{\lambda L \tilde{q}} \gamma_{t} \\
1-\beta_{R}=\lambda L \frac{1-\alpha}{\alpha} \frac{i_{t}}{r_{t}+\frac{\gamma_{t}}{\tilde{q}}} .
\end{gathered}
$$

The differential system (17)-(21) is very similar to the system governing the dynamics of Howitt and Aghion (1998). There are however three main differences, all of them related to the diverse nature of technological progress. First, consumption and capital grow at different rates along the balanced growth path, which is reflected by the terms containing $\gamma$ in (17) and (18). Second, under embodied technical change, the user cost of capital in (19) involves obsolescence costs, $\gamma_{t}$. Finally, under embodied technical change the expected value of $R \& D$, on the right hand side of (21), depends on investment, while in Howitt and Aghion it depends on final production. In the next sub-section, an economic interpretation is given to these differences.

Finally, let us define the average age of capital, which turns out to be central in our interpretation of the main mechanisms at work in this model:

$$
m(t)=\int_{-\infty}^{t}(t-z) \frac{I(z) e^{-\delta(t-z)}}{K(t)} d z .
$$

\subsection{The Balanced Growth Path}

We define a balanced growth path (BGP) as an equilibrium path along which $r_{t}, \gamma_{t}, c_{t}$, $i_{t}$ and $k_{t}$ are all constant. From (22) and after some substitutions, (17)-(19) and (21) becomes

$$
\begin{gathered}
\alpha k^{\alpha-1}=\frac{1}{\alpha}\left(r+\delta+\gamma-\beta_{K}\right) \\
1-\beta_{R}=\lambda L \frac{1-\alpha}{\alpha} \frac{\frac{k}{m}}{r+\frac{\gamma}{\widetilde{q}}} \\
r=\sigma \frac{\alpha}{1-\alpha} \gamma+\rho
\end{gathered}
$$




$$
m=\left(\frac{\gamma}{1-\alpha}+\delta\right)^{-1}
$$

Equation $(\mathrm{K})$ is the optimal condition for capital and it express the steady-state value of capital intensity as a function of the user cost of capital. Equation (A) is the arbitrage condition in the $\mathrm{R} \& \mathrm{D}$ sector, taking into account that $i=\frac{k}{m}$. Equation $(\mathrm{R})$ is the standard Fisher equation showing how the interest rate depends on the growth rate of consumption along the BGP. Finally, equation (M), simply states that the average age of capital must be equal to the inverse of the depreciation rate plus the growth rate of capital. The BGP can be first solve for $k$ and $\gamma$, after substitution of (R) and (M) in $(\mathrm{K})$ and $(\mathrm{A})$. Proposition 1, at the end of this sub-section, states sufficient conditions for existence and uniqueness of a positive rate of technical progress along the balanced growth path.

Our model has two main features. The first is related to the effect of obsolescence on the user cost of capital. As argued by Aghion and Howitt (1998), section 3.2.4, obsolescence costs mitigate any positive effect on long-run growth. The reason is straightforward. A rise in the rate of technical change increases the user cost of capital, by raising obsolescence costs. This increase in the user cost reduces the demand for capital, equation $(K)$. Since the expected value of $R \& D$ is positively related to the demand for capital, equation (A), a decrease in the later reduces the intensity of $R \& D$ activities and, consequently, the rate of technical progress. This is the obsolescence mechanism referred by Aghion and Howitt (1998).

The second feature is related to the crucial role of investment in the growth process. As mentioned before, our model predicts that the demand for investment goods, $i=\frac{k}{m}$, is a determinant of the research effort. This implies that a rise in investment stimulates innovation: More resources are devoted to $R \& D$, which increases the rate of embodied technical progress. An increase in the rate of technical progress has multiplicative effects by lowering the average age of capita, and inducing a further rise in investment, which in turn affects the rate of technological progress and the average age of capital. This is the modernization mechanism that the embodiment assumption gives rise to.

It is worth pointing out here that the embodied nature of technical progress is at the bases of the two key differences between our model and Howitt and Aghion (1998), where technical progress is disembodied. First, under disembodied technological progress and in contrast to the embodiment case, the obsolescence rate is zero and is not a determinant of the user cost of capital. Second, under disembodied technical progress the incentives to innovate depend on capital, while under embodiment they depend on investment only. In other terms, the modernization effect as depicted above only arise when technical progress is embodied, and it is crucial to understand the impact of capital subsidies on growth. This point is studied in section 3.

Before pursuing the analysis, let us first establish a sufficient condition for existence and uniqueness of a balanced path with positive growth. 
Proposition 1 If $L>\frac{\left(\delta+\rho-\beta_{K}\right)^{\frac{1}{1-\alpha}} \rho\left(1-\beta_{R}\right)}{\lambda \delta \Gamma}$, where $\Gamma=(1-\alpha) \alpha^{\frac{1+\alpha}{1-\alpha}}$, there exists a unique solution to the system $(K)-(M)$ with $\gamma>0$.

Proof: To prove existence and uniqueness of strictly positive solutions for $\gamma$, some tedious algebra is needed. Indeed after successive substitutions from equations $(\mathrm{K})$, $(\mathrm{R})$ and $(\mathrm{M})$ into $(\mathrm{A})$, we can write $\gamma$ as an implicit function of the sole parameters of the problem:

$$
1-\beta_{R}=\frac{\Gamma \lambda L\left(\frac{1}{1-\alpha} \gamma+\delta\right)}{\left[\left(\sigma \frac{\alpha}{1-\alpha}+\widetilde{q}^{-1}\right) \gamma+\rho\right]\left[\left(\sigma \frac{\alpha}{1-\alpha}+1\right) \gamma+\delta+\rho-\beta_{K}\right]^{\frac{1}{1-\alpha}}} \equiv \Lambda(\gamma)
$$

where $\Gamma=(1-\alpha) \alpha^{\frac{1+\alpha}{1-\alpha}}$. It is easy to check that function $\Lambda(\gamma)$ has the following properties: (i) $\Lambda(0)=\frac{\Gamma \lambda L \delta}{\left(\rho+\delta-\beta_{K}\right)^{\frac{1}{1-\alpha}} \rho}$, (ii) the limit of $\Lambda$ is zero when $\gamma$ tends to infinity, (iii) $\Lambda$ is continuous and strictly increasing in $L$ and (iv) there is at most one $\gamma>0$ such that $\Lambda^{\prime}(\gamma)=0$. From properties (i)-(iv) follows that for all $L>\frac{\left(\delta+\rho-\beta_{K}\right)^{\frac{1}{1-\alpha}} \rho\left(1-\beta_{R}\right)}{\lambda \delta \Gamma}$ there is only one strictly positive solution to $(23)$.

Proposition 1 states that labor resources should be large enough to a BGP with positive growth be sustainable. Though this kind of conditions is very often required in endogenous growth models (even in the simplest ones, see Romer, 1986), it is absolutely needed in our framework to additionally rule out multiplicity. Positivity of $k$ can then be easily showed. Finally, as in the standard growth model the condition $\rho>$ $(1-\sigma) \frac{\alpha}{1-\alpha} \gamma$ is required to get bounded utility, and it implies that $c$ and $i$ are strictly positive along the BGP.

\section{On the Impact of Subsidies under Embodiment}

In this section, the study of the impact on growth of capital and R\&D subsidies is restricted to BGP. As in Howitt and Aghion (1998), capital and research subsidies have both a positive effect on growth. This result is stablished in Proposition 2.

Proposition 2 If $\gamma>0$ at steady state, $\gamma$ increases when either $\beta_{K}$ or $\beta_{R}$ increases.

Proof: Proposition 2 follows directly from $(23)$ since $\Lambda(\gamma)$ is an increasing function of $\beta_{K}$ and the left hand side of (23) is a decreasing function of $\beta_{R}$.

Aghion and Howitt (1998), section 3.2.4, provide an intuitive explanation of the role of obsolescence in Howitt and Aghion (1998)'s framework. In order to do that, they modify Howitt and Aghion by adding the obsolescence cost to the user cost of 
capital, as we do in equation $(\mathrm{K})$, and found that capital intensity should be smaller at steady state. Consequently, they argue that an increase in capital subsidies has a lower positive effect on growth if obsolescence costs are to be considered. This paper shows that Aghion and Howitt's argument is incomplete, since it does not take into account the modernization effect of investment associated to the embodiment hypothesis. If it is taken into account, the rise in the rate of technical change due to capital subsidies yields indeed a decline in the average age of capital, which again stimulates research and growth. This additional mechanism may well rule out the main conclusion of Aghion and Howitt, namely the negative effect of embodiment on the efficiency of capital subsidies.

Proposition 3 establishes necessary and sufficient conditions for the positive effect of modernization more than compensate the negative effect of obsolescence.

Proposition 3 The modernization effect is larger than the obsolescence effect if and only if $r-\frac{\alpha}{1-\alpha} \gamma>\beta_{K}$.

Proof: The steady-state of $\gamma$ is implicitly defined by equation (23) as a function of $\beta_{K}$ and $\beta_{R}$. Differentiating (23), and after some algebra, we get

$$
\begin{gathered}
\frac{d \gamma}{d \beta_{K}}=\frac{\frac{1}{(1-\alpha) \widetilde{r}}}{\frac{\sigma \frac{\alpha}{1-\alpha}+\widetilde{q}^{-1}}{r+\gamma \widetilde{q}^{-1}}+\frac{\sigma \frac{\alpha}{1-\alpha}+1}{(1-\alpha) \widetilde{r}}+\underbrace{\frac{1}{(1-\alpha) \widetilde{r}}}_{\text {obsolescence }} \underbrace{-\frac{1}{(1-\alpha)}}_{\text {modernization }}} \\
\frac{d \gamma}{d \beta_{R}}=\frac{(\lambda \Gamma L)^{-1}\left(r+\gamma \widetilde{q}^{-1}\right) m \widetilde{r}}{\frac{1}{1-\alpha}} \\
\frac{\sigma \frac{\alpha}{1-\alpha}+\widetilde{q}^{-1}}{r+\gamma \widetilde{q}^{-1}}+\frac{\sigma \frac{\alpha}{1-\alpha}+1}{(1-\alpha) \widetilde{r}}+\underbrace{\frac{1}{(1-\alpha) \widetilde{r}}}_{\text {obsolescence }} \underbrace{\frac{1}{(1-\alpha)}}_{\text {modernization }}
\end{gathered}
$$

where $\widetilde{r}=r+\delta+\gamma-\beta_{K}$ is the user cost of capital. The modernization effect is higher than the obsolescence effect if only if

$$
\widetilde{r}>\frac{1}{m} \Leftrightarrow r-\frac{\alpha}{1-\alpha} \gamma>\beta_{K} \cdot \square
$$

A better understanding of Proposition 3 can be achieved by abstracting from the effects of $\gamma$ others than those operating through the obsolescence and the modernization mechanisms. From equation (A), an increase in the obsolescence cost rises the user cost of capital and reduces the demand for capital. The elasticity of the demand for capital with respect to the obsolescence cost is proportional to the weight of obsolescence costs in the user cost of capital. In order for the modernization effect to fully compensate 
the obsolescence effect, the demand for investment must remain unchanged after the induced reduction in the demand for capital. If not, the reduced incentives for $\mathrm{R} \& \mathrm{D}$ should lower the rate of technical progress. Indeed, investment could be accommodated by a reduction in the average age of capital, such that $\frac{\mathrm{d} k}{k}=\frac{\mathrm{d} m}{m}$. From (M), such a reduction requires the following relation $\frac{\mathrm{d} m}{m}=\frac{\gamma}{1-\alpha} m \frac{\mathrm{d} \gamma}{\gamma}$ to hold. Consequently, the positive effect of modernization fully compensates the negative effect of obsolescence costs if and only if the user cost of capital, $r+\gamma+\delta-\beta_{K}$, is equal to the inverse of the average age of capital, $\frac{\gamma}{1-\alpha}+\delta$. Nevertheless, if the user cost of capital is larger (smaller) than the inverse of the average age of capital, the modernization effect more (less) than compensate the obsolescence effect.

As stated at the end of sub-section 2.4, $\rho>(1-\sigma) \frac{\alpha}{1-\alpha} \gamma$ is required to get bounded utility. This condition is equivalent to $r-\frac{\alpha}{1-\alpha} \gamma>0$. Consequently, if capital subsidies are near to zero the modernization effect always dominates, and the positive effect of subsidies is larger under embodiment than under disembodied technical change.

\section{Conclusions}

This paper introduces capital accumulation and embodied technical progress into a Schumpeterian creative destruction model. We show that the embodied nature of technical progress has two main implications. First, the user cost of capital involves obsolescence costs, which affects negatively research activities. Second, the modernization of capital through investment raises the incentives to undertake R\&D activities. The modernization of capital is shown to offset the growth losses due to obsolescence costs, which in particular improves the growth enhancing role of subsidies.

Applied to the promotion of economic development, our results can serve to advocate the typical fiscal and trade policies ensuring the modernization of the capital stock. For example, capital subsidies are desirable under the strict condition that the purchased capital goods embody superior technologies. Though this policy is likely to generate relatively high obsolescence costs, the long term growth effects of the resulting modernization are likely to be high enough to compensate the latter costs. Naturally, such a modernization should take into account the necessarily limited capacity of technological absorption of the considered economies, of which the quality of the available skills is a key indicator. To address properly this issue, there is a need to construct less stylized models including a careful modelling of technological absorption capacity. This line of research is on top of our agenda. 


\section{References}

Aghion, P., and P. Howitt (1992), "A Model of Growth Through Creative Destruction," Econometrica 60, 323-351.

Aghion, P., and P. Howitt (1998), Endogenous Growth Theory, The MIT Press.

Bardhan, P. and R. Priale (1996), "Endogenous Growth Theory in a Vintage Capital Model," UC Berkeley, CIDER WP C96-069.

Barro, R., and X. Sala-i-Martin (1995), Economic Growth, McGraw Hill Inc.

Boucekkine, R., F. del Río and O. Licandro (2002), "Embodied Technological Progress, Learning and the Productivity Slowdown," Scandinavian Journal of Economics, forthcoming.

DeLong, B., and L. Summers (1991), "Equipment Investment and Economic Growth," Quarterly Journal of Economics 106(2), 455-502.

Denison, E. (1964), "The Unimportance of the Embodied Question," American Economic Review Papers and Proceedings 54, 90-94.

Greenwood, J., Z. Hercowitz and P. Krusell (1997), "Long-Run Implications of InvestmentSpecific Technological Change," American Economic Review 87, 342-362.

Hercowitz, Z. (1998), "The Embodiment Controversy: A Review Essay," Journal of Monetary Economics 41, 217-224.

Howitt, P., and P. Aghion (1998), "Capital Accumulation and Innovation as Complementary Factors in Long-Run Growth," Journal of Economic Growth 3, 111-130.

Hsieh, C. (2001), "Endogenous Growth and Obsolescence," Journal of Development Economics 66, 153-171.

Krusell, P. (1998), "Investment-Specific R\&D and the Decline in the Relative Price of Capital," Journal of Economic Growth 3, 131-141.

Licandro, O., J. Ruiz-Castillo and J. Durán (2001), "The Measurement of Growth under Embodied Technical Change," Recherches Economiques de Louvain, forthcoming.

Phelps, E. (1962), "The New View of Investment: A Neoclassical Analysis," Quarterly Journal of Economics 76, 548-567.

Romer, P. (1986), "Increasing Returns and Long-Run Growth," Journal of Political Economy 94, 1002-1037.

Romer, P. (1990), "Endogenous Technological Change," Journal of Political Economy 94, 1002-1037. 
Solow, R. (1956), "A Contribution to the Theory of Economic Growth," Quarterly Journal of Economics, 70, 65-94.

Solow, R. (1960), "Investment and Technological Progress," in Kenneth J. Arrow, Samuel Karlin and Patrick Suppes, Eds., Mathematical Methods in the Social Sciences 1959, Stanford University Press, 89-104.

Wolff, E. (1991), "Capital Formation and Productivity Convergence in the Long Run," American Economic Review 81, 565-579. 